\title{
Towards an interdisciplinary science of transport and health: A case study on school travel
}

Susan Hodgson ${ }^{a}$, Anil Namdeo ${ }^{b}$, Vera Araujo-Soares ${ }^{a}$, Tanja Pless-Mullolia

${ }^{a}$ Institute of Health and Society, Newcastle University, The Baddiley-Clark Building,

Richardson Road, Newcastle upon Tyne, NE2 4AX, United Kingdom

${ }^{\mathrm{b}}$ Civil Engineering and Geosciences, Newcastle University, Newcastle upon Tyne, United Kingdom

\section{Corresponding author:}

Prof Tanja Pless-Mulloli

Institute of Health and Society

Newcastle University

The Baddiley-Clark Building

Richardson Road

Newcastle upon Tyne NE2 4AX

United Kingdom

E mail: tanja.pless-mulloli@ncl.ac.uk

Telephone: +44 (0) 1912227211

Fax: +44 (0) 1912228752 


\section{Abstract}

Background and Aim: This paper was conceptualised and informed by discussions at the 2nd Workshop in a UKTRC funded series on 'Social Impacts and Equity in Transport'. Presentations made by a range of stakeholders as well as a specially commissioned play stimulated our thoughts on how to encourage better interaction between health and transport researchers. We chose school travel as a case study as it exemplifies two key aspects of the wider transport and health debates; (i) the increasing trend towards reliance on car travel, described here in the context of sedentary lifestyles, traffic congestion, pollution, and parental attitudes, and (ii) school travel occurs at a critical life-stage during which behaviour patterns are formed that are likely to be influential in later life, thus making it an important target point for interventions.

Methods: We present evidence from four distinct, but complementary, theoretical perspectives: transport, exposure, behaviour and sustainability. We draw common lessons and identify challenges using a range of conceptual frameworks: integrated psychological model of transport choices, Dahlgren and Whitehead's 'layers of influence' model, Hosking et al's 'pathways from transport to health', and Hanlon et al's integral theory. We demonstrate the benefits and challenges of holistic interaction and collaboration between disciplines to better understand the key issues and develop policy interventions that are meaningful and effective.

Results and conclusions: None of the pre-existing conceptual models were fully able to encompass the societal and individual level influences on school travel. However, we present an interim model for further discussion and debate.

\section{Key words:}

Transport, health, sustainability, behaviour change, transport choice, health behaviour

\section{Word count:}




\section{Highlights}

- Transport and health are interlinked on many levels

- School travel contributes to congestion and pollution, and impacts on health

- It also represents a critical life stage during which life-long behaviours are set

- School travel provides a valuable case study to explore numerous converging agendas

- There remain challenges to holistically considering this multi-dimensional issue 


\section{Introduction}

Transport and health are interlinked on many levels, with transport directly and indirectly influencing health, and health status influencing transport options.

Many of the positive and negative health consequences associated with transport are well acknowledged: Motorised vehicles are known as a source of localised air pollution and greenhouse gas emissions. Air pollution and greenhouse gas emissions in turn impact directly on respiratory and cardiac health in exposed populations (COMEAP 2006; Hoek et al. 2002; Le Tertre et al. 2002), and contribute to indirect health effects of climate change (World Health Organization 2009). Motorised transport also contributes to our increasingly sedentary lifestyle (Hill and Peters 1998), which in turn play a part in growing proportions of the population being overweight and obese. Numerous secondary health risks are associated with these conditions, including cardiovascular disease, type 2 diabetes, cancer, osteoarthritis and work disability.

Furthermore, road transport is directly responsible for a significant burden of morbidity and mortality; in Great Britain, in 2009, there were 163,554 road accidents reported to the police involving personal injury, and 2,222 traffic related deaths (National Statistics 2009). In contrast, 'active transport' (walking and cycling) is seen to be associated with a wide range of health benefits (Haskell et al. 2009; Johan de Hartog et al. 2010), and reduced greenhouse gas/air pollution emissions (Dennekamp and Carey 2010; Lindsay et al. 2011; Rissel 2009). However, despite the acknowledged benefits of active transport, there has been a 24 percent decline in the number of trips made on foot (292 to 221 trips per person per year 1995/97 to 2008; (Department for Transport 2009), and a decline in the number of primary and secondary school children walking to school (53 and 42\% in 1995/97 versus $48 \%$ and $40 \%$ in 2008) for primary and secondary school children respectively) (Department 
for Transport 2009). In the UK, up to $40 \%$ of the road traffic in the morning peak hour now estimated to be involved in some way in the school run (Mudu et al. 2006).

Our transport systems affect our ability to access work, education and services, as well as social activities, all of which are important for maintaining health and wellbeing. However, transport and transport availability is not equitably spread across the population. People on low incomes, in chronic ill-health, or with limited mobility may be less able to access or pay for the transport systems they need to acquire work, education and services (Jarvis and Alvanides 2008). Those on low incomes are also more likely to suffer the adverse effects of road traffic, for instance exposure to air pollution and noise (Marshall et al. 2009; Namdeo and Stringer 2008; O'Neill et al. 2003). Mitchell \& Dorling (2003) completed a comprehensive review of UK air quality social equity studies and concluded that most studies investigating the relationship between air quality and deprivation, tended to show that air pollution is greater in more deprived communities (Mitchell and Dorling 2003). These inequalities are complex (Briggs, David et al. 2008; Deguen and Zmirou-Navier 2010), but can be framed within the theory of environmental justice, in that some groups are disproportionately subject to environmental hazards and disadvantage predisposing them to poor health (Gee and Payne-Sturges 2004).

It is becoming increasingly recognised that patterns of behaviour established in infancy and childhood influence later behaviour, meaning that disadvantage in childhood may exert a lifelong health and social affect. Physical activity, smoking, and diet are socially patterned, with behaviours established in adolescence being shown to 'track' into adulthood (Due et al. 2011). In the context of travel and health, travel behaviours established in childhood may set the pattern for healthful or less healthful behaviours throughout the life course. However, a more detailed understanding of the development of such pathways is still very much needed to design effective, sustainable and acceptable policies that will encourage more healthful travel behaviour. 
In this paper we have outlined some key concepts related to transport and health; we use knowledge, skills and evidence from the areas of transport and exposure science, civil engineering, health psychology and behaviour change as well as sustainability, to reach an interdisciplinary understanding of the relations between transport and health set in the context of school travel in the developed countries.

\section{Materials and methods}

This paper was informed by discussions held at the 2nd Workshop in a UKTRC funded series entitled 'Social Impacts and Equity in Transport'. The series aimed to promote interdisciplinary collaboration and capacity building; to better equip researchers, policymakers and practitioners across the different social science and transport disciplines to address the social challenges of providing transport and access, and to maximise the social benefits of the transport system within the UK context, now and in the future. The 2 nd Workshop explored transport and health, and aimed to highlight both the linkages between transport and health, and between health and transport choices. The workshop, held over two days, brought together 27 participants from local councils, government agencies, academia, transport NGOs, the NHS, transport providers and transport consultancies, more details of the workshop, speakers and participants are available from the workshop report, which is available from the Transport Studies Unit website (Pless-Mulloli et al. 2011).

Discussion was stimulated by eight presentations made by representatives from local government, the NHS, transport providers, academics and transport relevant NGOs, as well as by a specially commissioned play entitled 'Doors Opening, Doors Closing' by playwright Carol Clewlow (www.ncl.ac.uk/ihs/news/item/?doors-opening-doors-closing1-copy1-copy). The play, set on a Metro carriage, explored the links between transport problems and 
general health and wellbeing. In the play regular Metro users converse with an occasional user, 'forced' to use the Metro as his car was being serviced. Regular users are widely differing characters - a female student, a cycle and Metro enthusiast, and a pensioner. The occasional user is a radio traffic reporter who loves his car. He talks about the advantages of using the car and sees his position challenged by the other characters who remind him of the state of the country's roads, of the constant queues and tailbacks that he reports about every day. Meanwhile the Metro stops on the tracks and Humankind's struggle for transport, and its implications on life are discussed. At the close of the play an interactive forum with the audience took place. The actors, remaining 'in character' were questioned by the audience to enliven further debate on issues associated with transport. The play, together with the scientific presentations, was able to communicate key concepts at different levels of knowing which mutually supported the learning from other disciplines. The idea was to bring together different perspectives, knowledge and experiences to generate discussion on the key issues and trends, and skills and policy needs, around this complex issue of transport and health.

A key methodological issue raised at the workshop was the need to encourage more interaction between health and transport researchers, and to develop methods to move the research and policy agendas forwards in a more holistic manner. Picking up on this suggestion in this paper we approach this need for interdisciplinarity by using the case study of school travel from a number of distinct, but complementary, theoretical perspectives, in an attempt to demonstrate the benefits of interaction between disciplines to better understand this important topic. 


\section{Results}

\subsection{Transport}

The journey to and from school is part of the everyday routine for most children, and for many parents or guardians who escort their children. As part of the trend towards adult supervision of children on journeys and at play, parents in Western societies are increasingly 'chauffeuring' their children to and from school (Davison et al. 2008; Dowling 2000; Valentine 1996). The UK Department for Transport estimated that a total of $41 \%$ of five to ten year olds in the UK travel to school by car (Department for Transport 2009). The proportion of children walking to school has declined, and car use for journeys to school has increased. Similar data from the US National Personal Transportation Survey revealed that the number of students who walked or cycled to school decreased from $41 \%$ in 1969 to only $13 \%$ in 2001 (McDonald 2007).

Another characteristic measured in transport surveys is the average journey length to school. According to the National Travel Survey (NTS) for Great Britain there has been an increase in the average journey length to school over the period $1985 / 86$ to 2004 by about 800 metres, although the average journey length remains short at about 2.3 kilometres for children under 11 and 4.7 kilometres for children aged 11-16 (Pooley et al. 2005). Increased car ownership is considered to be a major factor in the growth of school journey lengths (Department for Transport 2001).

This changing pattern in journeys to school has been linked not only to road safety and pollution but also to the fears of potential harm triggered at least in part by much-publicised child abductions and concerns about 'stranger dangers' (Matthews et al. 2000; Timperio et al. 2006; Valentine 1997). A set of powerful cultural expectations seems to have developed around parental roles, overwhelmingly falling to mothers, who feel the need to transport 
children between different activities. Sanger, 2005 suggested that in highly suburbanised Western cities, 'driving provide(s) evidence of good parenting and mileage the measure of maternal contribution to familial welfare' (Sanger 2005). This is symptomatic of the school run that is undertaken by many parents because it seems to make sense in terms of safety, family life and time/money budget constraints (Timperio et al. 2006).

In line with the impacts other users of transport experience, children encounter a range of hazards in the urban environment which have been well documented. Much focus has been on threats posed by motor vehicles, with growing traffic volumes linked to heightened risk of child pedestrian injury, as well as air pollution, noise and the loss of safe play spaces (Dixey 1998; Yeung et al. 2008). However, the growth in ownership and use of the 'freedom-giving' car has also been associated with a decline in children's freedom of movement and their ability to negotiate public space independent of adult supervision (Dixey 1998; Hillman 1993). It has been argued that similar barriers to use exist for young people when they consider transport modes: namely perceived reliability, convenience, cost, quality and safety (Yeung et al. 2008). Despite the accepted health benefits of walking (Lumsden and Mitchell 1999; Sjole and Thuen 2002; Wen et al. 2008), in some Western cities walking has become an almost counter-cultural activity, and 'a sign of powerlessness or low status' (Solnit 2000). The marginal status of walking is often accentuated by narrow (or non-existent) footpaths, heavy traffic volumes and a paucity of places to cross roads in safety.

When undertaken by car, school journeys can make a significant contribution to local traffic generation increasing congestion and pollution (Collins and Kearns 2001; Hillman 1995; Joshi and Maclean 1995; Kearns and Collins 2003; Sjole and Thuen 2002). The start of a new school year sees a $20 \%$ increase in traffic as a result of the 'school run' and in the last ten years the proportion of pupils participating in that run has almost doubled to an extra million every day (Department for Transport 2009). Pattern of school travel creates serious delays and bottlenecks close to schools with resultant safety issues. There is now an 
extensive geographical literature on traffic generation in towns, including the effect of the school run on urban congestion, and on potential strategies, including school travel plans, walking trains, safer route initiatives and cycling to schools, to reduce traffic volumes and create more sustainable urban transport systems (Docherty and Shaw 2003; Tolley 1990; Whitelegg 1997; 2003).

As more children are escorted to school by car their independence is reduced, and they are deprived of exercise that would otherwise be gained from walking to school. A recent systematic review conducted by Lubans et al to explore associations between active travel to school and health related fitness in children and adolescents found a positive association between active travel to school and cardio-respiratory fitness, though equivocal evidence for the relationship with muscular fitness or flexibility (Lubans et al. 2008). The health-promoting aspects of active travel to school are perceived by many parents to be offset by the safety concerns highlighted above (e.g. (Timperio et al. 2006), as well as time constraints (Black et al. 2001; Cooper et al. 2008; DiGuiseppi et al. 1998; Dixey 1998; Matthews et al. 2000). Some evidence suggests that walking or bicycling to school is associated with increased total physical activity among children. In a study of 114 children in Bristol, UK, Cooper et al. (2003) found that male youths who walked to school were significantly more physically active during the entire day and during after-school hours than were boys who did not walk to school (Cooper et al. 2003).

Issues of school transport and safety are currently the focus of much debate by policy makers, local authorities, schools, parents, pupils, the police and various interest groups. The House of Commons Transport Committee considered the issue of school transport in 2004 , concluding that congestion caused by parents undertaking the 'school run' in cars is unacceptably high and that procedures need to be implemented to encourage pupils to walk, cycle or use public transport for their journeys to and from school (House of Commons Transport Committee 2004). Schools across the UK have been responding to the challenge 
to adopt a new approach to the school run. Initiatives include a variety of ways to integrate road safety education into the school curriculum. Examples of 'best practice' in school transport provision from around the developed world include safer route initiatives, walking buses, cycling trains, school travel plans, travel co-ordinators, car sharing, the yellow school bus model, safe transport initiatives, education and resources, working on the assumption that a safer route makes children more likely to walk and cycle to school (Boarnet et al. 2005; Kingham and Ussher 2007).

In summary, there has been a trend over the past few decades for journeys to school to be made increasingly by car, and although journey length has increased, distances remain easily achievable using active forms of transport. The reasons behind this increasing car use are many, but include issues (real and perceived) of road safety, pollution, and child safety, as well as cultural expectations. A significant downside of the increased reliance on the car for school journeys is the associated decline in children's freedom of movement and independence, as well as a missed opportunity for exercise, with knock-on impacts on cardio-respiratory fitness and total physical activity. In an attempt to remedy the pollution, congestion and safety issues associated with the over-reliance on the car for these daily journeys, and to maximise the health benefits of active transport in school children, these issues are now the focus of debate by a wide range of stake holders, with various initiatives being implemented and evaluated in the UK and beyond.

\subsection{Exposure}

It is now well established that long term exposure to low levels of air pollution has a long term impact on health (COMEAP 2006), and that commuters and those travelling during 'rush hour' are likely to be exposed to relatively high concentrations of air pollution (Zuurbier 
et al. 2010). However, there is relatively sparse evidence quantifying pollution levels associated with different modes of transport in the context of school travel.

Although not specific to school travel, some studies have reported that walking and cycling, key components of active transport, compared to other forms of transport, are associated with exposure to lower levels of health relevant pollutants including particulate matter and carbon monoxide (Adams, H. S. et al. 2001; Du et al. 2010; Kaur and Nieuwenhuijsen 2009). However other studies have found the opposite to be the case, for example suggesting that walking is associated with exposure to higher levels of various particulate matter fractions than driving (Briggs, David J. et al. 2008; Mudu et al. 2006). Studies exploring pollution levels associated with different modes of travel in various locations around the world have also been relatively inconsistent, with many studies reporting transport mode to be important in determining exposure, but with transport modes being ordered differently, in terms of mean pollutant levels, depending on the pollutant of interest (Lee and Jo 2002; Zuurbier et al. 2010).

Whilst the evidence linking travel mode to pollution exposure does not all point in the same direction the evidence on pollution levels decreasing with distance from heavy traffic is consistent (Harrison et al. 2009; Johnson et al. 2000). Pollution levels are consistently associated with traffic volume (Harrison et al. 2009; Rotko et al. 2001). Season, route and ventilation of the vehicles (e.g. open windows) all influence the level of exposure (Lee and Jo 2002; Sabin et al. 2005; Zhu et al. 2007; Zuurbier et al. 2010). The interactions between these factors are likely to contribute to the inconsistencies observed in exposures associated with different transport modes described above.

While several studies have measured mean pollutant levels associated with different travel modes, the time spend in these different 'micro-environments' is another important factor determining exposure, which has been less explored. In the UK, in 2000, children were 
found to spend $5.4 \%$ of their time travelling (Office for National Statistics 2000). Therefore, while children spend relatively little time travelling, this time can still be an important source of pollution exposure. For instance, a study in Los Angeles found that although school bus commutes represented only $10 \%$ of child's day in terms of time, this commute contributed a third of the child's black carbon exposure on school days (Behrentz et al. 2005). While some (but not all) studies have found walking the same route to be associated with lower pollution levels than motorised modes of transport, the additional time taken to walk a route can mean that the cumulative exposure associated with this mode is higher than for other modes (Briggs, David J. et al. 2008). Clearly the route chosen may depend on the travel mode (i.e. if walking, school children may chose to walk a route with lower traffic volume), but, as stated above, the travel mode, route and micro-environment, in conjunction with other factors, all influence exposure. The time spent in a specific transport microenvironment is not the only factor determining exposure; breathing rates, which are likely to be higher for active modes of transport, will play a role in determining the quantity of air taken into the lungs, and will therefore also influence exposure and dose (Kaur and Nieuwenhuijsen 2009). Taking these factors into account suggest that pedestrians might have a higher air pollution exposure than car occupants, however this exposure is likely to be offset by other health related advantages, such as generally being more active (Mackett and Paskins 2008; van Sluijs et al. 2009) and opportunities for socialisation (Mudu et al. 2006).

Proximity to road traffic, like many of the factors mentioned above, is socio-economically patterned. Whilst in developing countries proximity to roads is seen as providing access to transport, in the developed world those who can afford it are likely to choose living away from busy roads and traffic, with more deprived individuals tending to live in areas closer to heavy traffic and/or high traffic volumes (Marshall et al. 2009).

This suggests that there might be an additional socio-economic impact influencing exposure within the same mode of transport (i.e. walking in a deprived (high traffic) area might confer 
higher exposure than walking in an affluent (traffic calmed) area, although to date little research has been carried out to explore this. Studies also suggest that socio-economically disadvantaged groups are more reliant on active transport (Adams, Jean 2010) and active transport for school travel (Jarvis and Alvanides 2008). These inequalities in exposure and choice of transport mode are likely to contribute to the environmental injustice faced by more deprived groups. Furthermore, these inequalities may be exacerbated by 'choices' more available to others. For instance, school choice policies, as an alternative to children being assigned to neighbourhood schools, have been embraced by more affluent groups, often at the cost of attending a school further from their place of residence, requiring a return car or bus journey to be made, increasing traffic volume, congestion and exposure experience by others (Jarvis and Alvanides 2008; Wilson et al. 2007).

In summary, exposure to air pollution has an impact on health, and commuters, including children travelling to school, are likely to be exposed to relatively high levels of various air pollutants. Although children spend a relatively short proportion of their time engaging in school travel, this time can still be an important source of pollution exposure. Different transport modes are associated with different levels of air pollution exposure, influenced by a variety of factors including distance from heavy traffic, traffic volume, season, route, ventilation and breathing rates. Some of these factors are socio-economically patterned, with more deprived individuals tending to live in areas closer to heavy traffic and/or high traffic volumes, and with some evidence showing that disadvantaged groups are more reliant on active transport and active transport for school travel, potentially exacerbating inequalities in health relevant exposures.

\subsection{Behaviour}

Understanding how individuals and families make transport choices based on current socioeconomic, cultural and environmental conditions is key to influencing travel behaviours. 
Behavioural science has developed a range of theories, intervention techniques and evaluation paradigms which have the potential to contribute to our understanding of how individuals make transport choices, how these choices are constrained by the socio-cultural environment and how these choices can be supported and modified through policy and other level interventions (Michie et al. 2011). Transport-oriented policies/interventions can have a great impact on behaviour change. The Behaviour Change Wheel described on the Michie and col. 2011 paper, cited above, describes distinct intervention (activities designed to influence behaviour) functions. These can include education, persuasion, training and modelling on one hand and incentivisation, coercion, restriction, environmental restructuring and enablement on the other. Intervention development can emerge from legislation brought up by political authorities and/or can act by supporting individual/family decision making. This knowledge can support intervention development.

In a systematic review of interventions to promote walking (Ogilvie et al. 2007) a small non randomised trial of an active commuting pack, found a significant increase in self-reported walking on the school journey amongst 9-year old school children (McKee et al. 2007). The intervention included written curriculum materials on active travel for teachers to use during school classes as well as children and family information packs that aimed to support the planning of active journeys to school. Intervention strategies included: goal setting for changing travel to school; self monitoring via an activity/transport diary, and; information on how to be a safe pedestrian. These results demonstrate that a behavioural intervention might be effective in facilitating active travel to school. However, another systematic review targeting organisational travel plans included 10 intervention studies delivered in school settings (Hosking et al. 2010) and did not find evidence for the effectiveness of the interventions, including the installation of a school travel coordinator (Rowland et al. 2003) or a complex intervention targeting student, teachers, parents and councils in Australia (Web et al. 2010). 
This brief review of interventions demonstrates that knowledge about how to influence transport choice is limited to date. Methodological quality of studies has been variable, interventions tested to date have not utilised evidenced theory of behaviour change and intervention techniques used are usually poorly reported (Dombrowski et al. in press). Interventions used a limited set of change techniques mainly focussing on (i) providing opportunities for behaviour change (e.g. safe walking or cycling routes; walking bus); (ii) engineering measures (e.g. pedestrian crossings and footpaths improvements); (iii) promotional measures for alternative transport (e.g. walk to school days), or; (iv) educational measures (e.g. focus on the benefits of active transport). However, there are great opportunities for knowledge transfer utilising existing theories (Web et al. 2010) and behaviour change techniques (Abraham and Michie 2008; Michie et al. In press ) established and evidenced in the field of health related behaviour change.

Partaking in active transport for school travel, i.e. walking or cycling with a child to school, is a behaviour that is ultimately influenced by a range of policy and socio-cultural factors constraining the available options while still leaving degrees of freedom for individual choice. Psychological theory suggests that environmental and contextual factors interact with individual factors to explain inter-individual and intra-individual variability in transport choice. There is now compelling evidence that human behaviour is directed both by reflective and reasoned as well as impulsive and often unconscious modes of decision making (e.g. habits and impulsive/automatic responses to environmental stimuli) to shape behaviours (Hofmann et al. 2008; Strack and Deutsch 2004). Moreover, self-regulation strategies can be used to override impulsive forms of responding in favour of more intentional choices. Figure 1 illustrates the relationships between the environmental/contextual, reflective, and impulsive modes of decision making and self-regulation, which are described in brief below. 


\subsubsection{Reflective decision making}

The common idea of decision making is that of an expectancy value model (Fishbein 1967). According to this model, individuals hold expectations about the consequences of various options, and weigh up the pros and cons, estimate the chances that these consequences will occur, and chose the option which gives them the best value with the highest likelihood. While we know today that human decision making is not as systematic as this model suggests (Gigerenzer 2000; Kahneman and Tversky 1973), the two main ideas that people chose options which have more pros than cons (e.g., outcome expectations, expected utility) and are achievable (controllability; self-efficacy) are well supported by evidence (Ashford et al. 2010; Bandura 1997; Schoemaker 1982). In terms of outcomes and utility, there is evidence that people are more likely to respond to immediate, certain, positive and affective outcomes than to long-term, uncertain, negative and cognitive outcomes (Conner et al. in press). With respect to school travel, choosing what is perceived as a familiar, convenient and controllable option (e.g. the car) might often be prioritised over active transport options, despite these alternatives being widely acknowledged as better for long term health or the environment.

Initial transport decisions may indeed often be made on a reflective basis. Consider, for example, a family who, for the first time, are deciding how to escort their children to school. For this initial occasion a number of relevant factors are considered and weighted such as distance to school, road safety, quality of the footpaths, traffic congestion, and time constraints (Black et al. 2001; Cooper et al. 2008; DiGuiseppi et al. 1998; Dixey 1998; Matthews et al. 2000). The structures and organization of our cities, towns and neighbourhoods will influence this initial decision and will make it more likely, for a family with a heightened perception of negative outcome expectancies and perceived low selfefficacy on walking or cycling to school, to decide for the car. These expectations might not 
necessarily match to people's outcome experiences. In sum, salience, attractiveness, access, proximity and costs of distinct transport mode options are some of the features that can determine our initial choices.

\subsubsection{Associative modes of behavioural decision making}

Not all behaviours are driven by reflective decision making; habits are automatic responses to environmental stimuli acquired through repeated performance in a specific context (Triandis 1977). Habits are an adaptive mode of behavioural regulation allowing shortcuts in decision making without using limited cognitive resources (Lally et al. 2010). When facing the context (acting as the cue) the automatic response will be the habitual behaviour. After initial transport choices have been made, the daily commute to school is likely to develop habitual features, e.g., no need for active intent, control or awareness (Bargh 1994). Once behavioural habits are in place, families might maintain their regular mode of transport, even if everyday experiences are unfavourable (e.g. continued car use by habit, even if traffic congestion makes this an unreliable choice). Life span associated changes, including starting school, moving from primary to secondary school, or even policy induced contextual changes can be a crucial window for behaviour change and allow for the dissolution of old habits through the use of active self regulatory strategies.

\subsubsection{Changing transport behaviours}

Regular transport behaviours are likely to be the result of habits or associative responses to environmental cues (e.g., weather). Methods to change automatic behaviours might therefore include:

i) Prompting a conscious review of the ease and expected outcomes/utility of the full range of available transport options, for example using a 'decisional balance sheet' listing the pros and cons of the options with a focus upon affective, proximal and immediate outcomes (enjoyment, relaxation, experience) of each option. 
ii) Validating beliefs about expected outcomes/utility and ease of use. Beliefs held about transport modes are not necessarily accurate and in correspondence with experienced outcomes/utilities. Prompting a reflection comparing expected and experienced outcomes/utility using experience sampling (Hektner et al. 2007), ecological momentary assessment tools that elicit self monitoring in real time settings (Shiffman et al. 2008) or simple self-monitoring diaries can help re-evaluate choices and make better decisions, based on a review of the salience of alternative transports.

iii) Changing utility structures of transport choices. Environmental changes (e.g. brought about by policy measures) that increase the perceived utility of one choice over another making healthful options easier, safer, cheaper, more attractive and socially accepted. iv) Supporting self regulation. Although families may have good intentions to use sustainable and active transport modes, they may succumb to the temptation of using the car if they are running late or when it is raining. Simple self regulation techniques, such as prompting people to actively remember the reasons for their choices and challenging the temptations to violate these reasons by setting goals and forming action/coping plans (e.g. having rain gear readily available) (Sniehotta 2009) might help people persevere with good intentions in situations where time pressure and stress make active reflections more difficult.

In summary, changing transport behaviours can be achieved through external policy, environmental and individual interventions (Michie et al. 2011). An understanding that not all day-to-day transport decisions are made based on reflection and deliberation helps to direct these efforts to interrupt habits and automaticity and set the ground for new, better decisions. Taxonomies for scientific methods for changing individual behaviours have been worked out for physical activity and dietary behaviours (Michie et al. In press ). It would be useful for the field of transport behaviours to establish a similar framework to be able to fully describe and better report the methods used to affect transport choices. 


\subsection{Sustainability}

Considering school transport and health in the context of sustainability is still very novel. As is illustrated in the previous sections there are bodies of evidence from the fields of transport research, exposure science, behaviour science, and public health, however they are not commonly contextualised within sustainability as a framework. The terminology of cobenefits between air pollution and climate change policies and management has been used for a number of years and is reflected in a body of evidence (Chapman 2007; Creutzig and He 2009; Thambrian and Dian 2011), but none of these papers considered school travel as an example or case study.

McMichael et al. argued in 2003, that "much early discussion about sustainability has focused on readily measurable intermediate outcomes such as increased economic performance, greater energy efficiency, better urban design, improved transport systems, better conservation of recreational amenities, and so on. However, such changes in technologies, behaviours, amenities, and equity are only the means to attaining desired human experiential outcomes, including autonomy, opportunity, security, and health. These are the true ends of sustainability' (McMichael et al. 2003).

A recent paper by (Hosking et al. 2011) entitled: 'How can we best intervene in the trip to school? Pathways from transport to health' goes a long way in developing a conceptual model of the decisions that contribute to the choices on how school journeys are being made whilst simultaneously considering health improvement and sustainability. The diagram they developed in the paper conceptualised how interventions directed at multiple levels can influence school travel and consequently health. This model included interventions at six levels; the global, national, city, neighbourhood, school and family levels. These six levels of intervention influence both the quantity and quality of school transport decisions (i.e. the number of walking trips to and from school), which influence travel related factors such as 
the quality and quantity of travel, which in turn influence health risk factors, such as physical activity, air and noise pollution, road safety, social capital and networks, and independent mobility, which determine the health outcomes of children travelling to school. While this model covers many of the critical concepts which we have touched on in the previous sections of this paper, there are omissions and interactions that we would propose should be added to create a more holistic model of school travel in the context of sustainability.

For the global level of intervention climate change is listed as an example, however we would argue that global policies to reduce energy use overall and to minimise reliance on carbon based fuel sources should be added to this model providing a direct link into the sustainability agenda. Policies aimed at reducing emission and transport policies are listed as National level interventions. We would argue that policies related to, for example, the licensing of industries, and planning policies that determine the location of schools and residential developments are influential in determining contextual and environmental conditions that determine the possibility and ability of children to walk to school. The six levels of influence as shown in Hosking et al's diagram do not show the interdependence of these levels of influence. It is easy to see how global, national, city-wide influences impact on school and family level factors of transport choices. However, it can be argued that there is some upward influence as well.

Hosking et al argue that at each stage, from interventions to health outcomes, the distribution of factors such as socio-economic position or ethnicity can influence inequalities in the health outcomes. Furthermore, some intervention effects are experienced primarily by children travelling to and from school, such as the benefits of more physical activity, whilst others such as reduced traffic volume provide benefits to the wider population by improving air quality and reducing risk of road traffic accidents for all. A good example of this interconnectedness of pro-sustainable and health improving choices was reported by in Giles-Corti et al. who investigated the impact of neighbourhood walkability in the vicinity of 
the school site and the potential to walk to school in Australia (Giles-Corti et al. 2011). Children were more likely to regularly walk to school if they attended a school in a highly walkable neighbourhood (high street connectivity and low traffic volume), but less likely to walk if they attended a school with high connectivity and but high traffic volume, highlighting the importance of planning and street design in the vicinity of schools.

The convergence of policy and research agendas or the co-benefits from public health and sustainability science in the area of school transport can be well illustrated for the field of childhood obesity and physical activity. Policy measures that aim to increase physical activity and reduce consumption of processed foods such as walking to school and increasing the use of locally produced foods also meet sustainability targets on energy and food miles. The potential for joint polices and joint research is not yet widely visible, and there is still much fragmentation in both arenas. An aspirational policy example that is more holistic in its approach is the 2008 Scottish strategy document 'Good places, better health', outlining a new approach to environment and health in Scotland (The Scottish Government 2008), which puts great emphasis on contextual and place influences on health and wellbeing, and aims at generating convergence between previously disjointed levels of intervention. It seeks to frame problems with reference to environment and place in a way that represents all the factors that bear upon it.

In summary, while there exists great potential to derive co-benefits for sustainability and health by influencing school travel, more work is needed to bring together the growing evidence from a range of disciplines to ensure these benefits can be realised and maximised. Policy levers at a range of levels to reduce energy use and emissions, influence planning decisions regarding the locations and accessibility of our schools etc can be used to create an environment that will support decision making and behaviour change as outlined above, but these policies, and the research to support and evaluate their effects, need to be joined up. 


\section{Discussion}

We started this paper from a premise of the many levels of links between transport and health, using school travel as case study. In doing so we have highlighted some of the evidence of the health consequences associated with school transport, including the impacts of motorised transport on air pollution and greenhouse gas emissions, in contributing to our increasingly sedentary lifestyles, and to road accidents, all of which have direct or indirect impacts on health. We have also briefly explored how 'active' transport is associated with 'co-benefits' of reduced air pollution/greenhouse gas emissions and increased exercise and better health. However, our modern western lifestyles and behaviours are seemingly reducing opportunities for these co-benefits to be realised, with fewer trips, including school journeys, being made on foot. The issues of travel and health are interwoven with issues of equity in a complex way, be that social, economic or health-related equity. Consequently, some groups are less able to access or pay for the transport systems they need to acquire work, education and services, all of which are necessary to maintaining health and wellbeing. Transport choices can indeed exacerbate inequalities, or even generate them, for instance increasing school choice can increase traffic flows, with accompanying increases in air/noise pollution, and higher risk of accidents, disproportionately affecting those sections of society less able to act upon these 'choices' being offered to them. We have also illustrated how influencing travel behaviour to encourage more healthful choices is a complex challenge, requiring a deep understanding of decision making, habit, and self-regulation, the impact of context and environments in shaping decisions, as well as an appreciation of the stages during life when interventions might be best enacted.

It seems that in the developed world we have created a situation for ourselves, exacerbated by urban design planning and policy, where, in order to lead a 'fulfilled' modern life 
encompassing a career, childcare and schooling, we need to make constant journeys between key locations, such as home, work and school, on a daily basis. Our 'choice' of transport mode is influenced not just by cost, convenience and habit, but also by societal and cultural values attached to these different travel modes. For many years now it seems that cars have been viewed as more convenient, safe and reliable than public transport or active transport, which, when coupled with the increasing distances between home, school, and work, is likely to explain much of the ongoing trend of an increase in car journeys/decrease in active journeys noted above. While this prevailing view shows no immediate sign of changing, there is perhaps a growing recognition that there are numerous impacts associated with our travel between these locations, including pollution, climate change, congestion and road safety issues, as well as a direct impact on those to whom these transporting responsibilities fall, in terms of time, resource, money and stress. With 'sustainability' now a widely recognised higher order goal, and with the development of policy at a range of levels to achieve the true ends of sustainability; namely autonomy, opportunity, security, and health (McMichael et al. 2003), it might be expected that the balance will shift back in favour of active or public forms of transport. Sustainability is capable of bringing direct co-benefits to health (i.e. interventions to reduce carbon emissions from car-travel by increasing active transport will also bring co-benefits of reduced obesity), but may also be a powerful motivator for behavioural change, and increasingly our infrastructures in society (including policy, laws etc) that support people to change are (or should be) in accordance with sustainable goals.

In writing this paper jointly with our backgrounds in the areas of transport and exposure science, health psychology and behaviour change, and sustainability we aimed to more fully and better understand the complexities of the links between transport and health in the context of school travel. We have found this aim to be more challenging than expected, and found it difficult to bring our disciplinary based views together in a truly holistic way. Nonetheless, we have gained various insights into the nature of some of the challenges we 
face when trying to meaningfully tackle issues of transport and health, and three of these are discussed in brief below.

One insight made obvious to us as a consequence of participating in the UKTRC Workshop and working together on this paper was that success in understanding transport and health issues will only be forthcoming if we, as researchers, are able to move beyond our separate disciplines, constrained as they are by subject specific terminology and methods, restricted scope, and limited outcomes or measures of success. The need to break this 'silo' thinking is not limited to researchers; systems at an institutional and governmental level prevent or at least complicate the adoption of the kind of holistic approach that is needed to tackle these complex issues. For example, recent government initiatives such as the Local Sustainable Transport Fund (LSTF) focus unduly on achieving goals related to sustainability. Value could have been added to this same initiative if co-benefits of sustainability, for example health benefits, were also brought to the fore, encouraging links between different disciplines, and enabling the wider benefits of adopting a sustainable agenda to be appreciated.

A second insight, highlighted well by the Workshop's specially commissioned play, was identifying the various layers of assumption we make about transport and transport behaviour, as individuals, researchers, government and society. By working together to appreciate the costs and benefits that might fall beyond our own limited experiences or fields of expertise we can start to unpack these assumptions to make more balanced judgements about the pros and cons associated with the transport choices we make and/or values we assign to these travel modes.

A third insight was an appreciation of how quickly this field of research is moving forwards, as evidenced by the numbers of research publications being produced on this topic, as well as government funds to support research to progress the field further. While these indicators clearly signal a timely acceptance of the importance of transport and health issues, a 
recurring theme from the discussions at the Workshop was the continued failure of governmental and institutional initiatives and/or interventions to consult widely enough in the formative stages to maximise potential benefits, and/or a failure to adequately assess their efficacy using a range of outcome measures, from a range of disciplines, including measures of health and wellbeing that are not easily captured by standard metrics such as economic costs/benefits and/or life years saved.

For this discussion we tried various approaches and frameworks to draw the evidence and viewpoints together in a meaningful manner. The models we have chosen to draw upon were those familiar to our respective backgrounds and/or interesting models and concepts we came across while researching this paper. First, we adapted the Dahlgren and Whitehead 'layers of influence' social model of health (Dahlgren and Whitehead 1991) to show how age, sex and constitutional factors, set within a context of individual lifestyle factors; social and community networks; living, working and schooling conditions; and broad socio-economic, cultural and environmental conditions, can act as influences on the transport choices we make (or have imposed upon us). This model has previously been adapted to create the 'Settlement Health Map', in an attempt to provide a holistic model of the relationship between people, their quality of life, and their local and global environment (Grant and Braubach 2010). Our version focussed specifically on factors influencing or being influenced by school transport, and while this approach encapsulated some of the myriad influences on lives and lifestyles, acting at a range of levels, it did not allow for pathways by which these factors act to be emphasised, nor how these factors might determine health and wellbeing. In an attempt to incorporate some of these key pathways we expanded the model developed by Hosking et al. 2011, to demonstrate how interventions, at the global, national, city, neighbourhood, school and family levels, can influence school travel and health. While these models combined went some way towards demonstrating the numerous and complex influences of transport and health, the model was not entirely satisfactory as there was insufficient emphasis on the socio-economic, cultural, political and environmental conditions 
influencing travel behaviours. To try to address this limitation, we attempted to additionally incorporate the concepts of integral theory and the key dimensions of human experience subjective/interior versus objective/exterior, and individual versus collective - as they relate to public health, based on the work of Hanlon et al (Hanlon et al. 2010). In Hanlon's paper the importance of simultaneously considering all dimensions in the model is stressed, 'all key dimensions of human experience need to be considered, harmonised and acted on as a whole' otherwise public health efforts (e.g. increasing active transport in line with sustainable goals) may be undermined by the influence of forces from the lesser known dimensions.

The end result, a work in progress that is likely to evolve further, is a layers-like model, with explicit interactions between the different spheres of influence and an acknowledgement of the need for integrative thinking (figure 2). We have set Dahlgren and Whitehead 'layers of influence' at the core, with individuals and families, their resources, habits and behaviours being affected by local and regional school siting and transport policies, which in turn are influenced by local and regional planning, design and intervention, which are themselves a consequence of national and global policy. To highlight the interconnectedness of these layers of influence and to make the explicit link to health, we have adopted key elements of Hosking's model to show that the various layers of influence can shape an individual's and community's choices, including travel mode, transport volume and frequency of trips, which in turn determines levels of activity, pollution, social connectivity and so on, which are key determinants of health and wellbeing. We set this combined 'layers of influence' model plus explicit pathway to health within a further dimension, based on Hanlon's concepts of integral theory, to emphasise the socio-economic, cultural, political and environmental conditions that influence travel behaviour, and highlight the need to address the complex issue of transport and health holistically.

Figure 2 here 
To be able to holistically tackle this important issue of transport and health we need to find ways of considering the many dimensions feeding into this issue. To achieve this, we acknowledge that we need to move beyond working in our separate 'silos' of research on transport, exposure, behaviour, public health etc. There is no easy way of achieving this, and as with all trans-disciplinary research areas there are challenges to overcome, including subject specific terminology and jargon, different methods and scales of working, and different knowledge bases to build on. These challenges need to be overcome; it is only by continuing to work together in an integrated fashion, using an evidence-based approach, that we can make a leap forwards in terms of understanding the interconnectedness of the many facets of this problem, to develop interventions that will benefit health and sustainability.

\section{Acknowledgements}

This workshop and workshop series which hosted the discussions that led to this paper were supported by the UKTRC, with funding from DfT, Scottish Government, and ESRC. 


\section{References}

Abraham, C. and Michie, S. 2008. A taxonomy of behaviour change techniques used in interventions. Health Psychology Review 27, 379-387

Adams, H.S., Nieuwenhuijsen, M.J., et al. 2001. Fine particle (PM2.5) personal exposure levels in transport microenvironments, London, UK. Science of the Total Environment 279(1-3), 29-44

Adams, J. 2010. Prevalence and socio-demographic correlates of "active transport" in the UK: analysis of the UK time use survey 2005. Preventive Medicine 50(4), 199-203

Ashford, S., Edmunds, J., et al. 2010. What is the best way to change self-efficacy to promote lifestyle and recreational physical activity? A systematic review with meta-analysis. British Journal of Health Psychology 15, 265-288

Bandura, A. 1997. Self-efficacy: the exercise of control. New York, W.H. Freeman.

Bargh, J.A. 1994. The Four Horsemen of automaticity: Awareness, efficiency, intention, and control in social cognition. In: R. S. Wyer and T. K. Srull (Eds). Handbook of social cognition. Hillsdale, NJ, Erlbaum.: 1-40.

Behrentz, E., Sabin, L.D., et al. 2005. Relative importance of school bus-related microenvironments to children's pollutant exposure. Journal of the Air \& Waste Management Association 55(10), 1418-1430

Black, C., Collins, A., et al. 2001. Encouraging walking: the case of journey to school trips in compact urban areas Urban Studies. 38, 1121-1141

Boarnet, M.G., Anderson, C.L., et al. 2005. Evaluation of the California Safe Routes to School legislation: Urban form changes and children's active transportation to school. American Journal of Preventive Medicine 28(2, Supplement 2), 134-140 
Briggs, D., Abellan, J.J., et al. 2008. Environmental inequity in England: small area associations between socio-economic status and environmental pollution. Social Science \& Medicine 67(10), 16121629

Briggs, D.J., de Hoogh, K., et al. 2008. Effects of travel mode on exposures to particulate air pollution. Environment International 34(1), 12-22

Chapman, L. 2007. Transport and climate change: a review. Journal of Transport Geography 15, 354367

Collins, D. and Kearns, R. 2001. The safe journeys of an enterprising school: negotiating landscapes of opportunity and risk. Health and Place 7, 293-306

COMEAP 2006. Cardiovascular Disease and Air Pollution A report by the Committee on the Medical Effects of Air Pollutants. Department of Health

Conner, M.T., Rhodes, R., et al. in press. Changing exercise through targeting affective or cognitive attitudes. Psychology \& Health

Cooper, A.R., Page, A.S., et al. 2003. Commuting to school: are children who walk more physically active? Am J Prev Med 25, 273-276

Cooper, A.R., Wedderkopp, N., et al. 2008. Longitudinal associations of cycling to school with adolescent fitness. Prev Med 47, 324-328

Creutzig, F. and He, D. 2009. Climate change mitigation and co-benefits of feasible transport demand policies in Beijing. Transportation Research Part D: Transport and Environment 14, 120-131

Dahlgren, G. and Whitehead, M. 1991. Policies and strategies to promote social equity in health. Stockholm, Institute of Futures Studies

Davison, K.K., Werder, J.L., et al. 2008. Children's active commuting to school: current knowledge and future directions. Preventing Chronic Disease 5(3), A100 
Deguen, S. and Zmirou-Navier, D. 2010. Social inequalities resulting from health risks related to ambient air quality - A European review. European Journal of Public Health 20(1), 27-35

Dennekamp, M. and Carey, M. 2010. Air quality and chronic disease: why action on climate change is also good for health. New South Wales Public Health Bulletin 21(5-6), 115-121

Department for Transport 2001. National travel survey: 1999/2001 update. N. Statistics. London

Department for Transport 2009. Transport Trends: 2009 Edition

DiGuiseppi, C., Roberts, I., et al. 1998. Determinants of car travel on daily journeys to school: crosssectional survey of primary school children. British Medical Journal 316, 1426-1428

Dixey, R. 1998. Transport modes for the journey to school. Traffic Engineering and Control 39(6), 363

Docherty, I. and Shaw, J. 2003. A new deal for transport? Oxford, Blackwell.

Dombrowski, S.U., Sniehotta, F.F., et al. in press. Effects of specific behaviour change techniques on behaviour and weight change: A systematic review. Health Psychology Review

Dowling, R. 2000. Cultures of mothering and car use in sub-urban Sydney: a preliminary investigation. Geoforum 31, 345-353

Du, X., Kong, Q., et al. 2010. Characterization of personal exposure concentration of fine particles for adults and children exposed to high ambient concentrations in Beijing, China. Journal of Environmental Sciences (China) 22(11), 1757-1764

Due, P., Krolner, R., et al. 2011. Pathways and mechanisms in adolescence contribute to adult health inequalities. Scandinavian Journal of Public Health 39(6 Suppl), 62-78

Fishbein, M. 1967. Attitude and the prediction of behaviour. In: M. Fishbein (Eds). Readings in attitude theory and measurement. New York, Wiley. 
Gee, G.C. and Payne-Sturges, D.C. 2004. Environmental Health Disparities: A Framework Integrating Psychosocial and Environmental Concepts. Environmental Health Perspectives 112(17), 1645-1653

Gigerenzer, G. 2000. Adaptive thinking: Rationality in the real world. Oxford, Oxford University Press.

Giles-Corti, B., Wood, G., et al. 2011. School site and the potential to walk to school: The impact of street connectivity and traffic exposure in school neighbourhoods. Health and Place 17, 545-550

Grant, M. and Braubach, M. (2010) Evidence review on the spatial determinants of health in urban settings. Annex 2 in urban planning, environment and health. Urban planning, environment and health: From evidence to policy action. Meeting report . pp. 22-97. Available from http://www.euro.who.int/_data/assets/pdf_file/0004/114448/E93987.pdf

Hanlon, P., Carlisle, S., et al. 2010. Enabling well-being in a time of radical change: Integrative public health for the 21st century. Public Health 124(6), 305-312

Harrison, R.M., Delgado-Saborit, J.M., et al. 2009. Measurment and Modeling of Exposure to Selected Air Toxocs for Health Effects Studies and Verification by Biomarkers. HEI Research Report 143. H. E. Institute. Boston, MA

Haskell, W.L., Blair, S.N., et al. 2009. Physical activity: health outcomes and importance for public health policy. Preventive Medicine 49(4), 280-282

Hektner, J.M., Schmidt, J.A., et al. 2007. Experience Sampling Method: Measuring the Quality of Everyday Life. Thousand Oaks, CA, Sage.

Hill, J.O. and Peters, J.C. 1998. Environmental contributions to the obesity epidemic. Science 280(5368), 1371-1374

Hillman, M. 1993. Children, transport and the quality of life. London, Policy Studies Institute Hillman, M. 1995. Rejoinder to parental attitudes to children's journeys to school by Mary Sissons Joshi and Morag Maclean. World Transport Policy and Practice 1, 37 
Hoek, G., Brunekreef, B., et al. 2002. Association between mortality and indicators of traffic-related air pollution in the Netherlands: a cohort study. Lancet 360(9341), 1203-1209

Hofmann, W., Friese, M., et al. 2008. Impulsive versus reflective influences on health behavior: a theoretical framework and empirical review. Health Psychology Review 2(2), 111-137

Hosking, J., Ameratunga, S., et al. 2011. How can we best intervene in the trip to school? Pathways from transport to health. Australian and New Zealand Journal of Public Health 35(2), 108-110

Hosking, J., Macmillan, A., et al. 2010. Organisational travel plans for improving health (Review). The Cochrane Library (3)

House of Commons Transport Committee 2004. Eighth Report: School Transport, HC318-I. Stationery Office. London, House of Commons

Jarvis, H. and Alvanides, S. 2008. School choice from a household resource perspective: Preliminary findings from a north of England case study. Community, Work \& Family 11(4), 385-403

Johan de Hartog, J., Boogaard, H., et al. 2010. Do the health benefits of cycling outweigh the risks? Environmental Health Perspectives 118(8), 1109-1116

Johnson, T., Long, T., et al. 2000. Prediction of hourly microenvironmental concentrations of fine particles based on measurements obtained from the Baltimore scripted activity study. Journal of Exposure Analysis and Environmental Epidemiology 10(5), 403-411

Joshi, M. and Maclean, M. 1995. Parental attitudes to children's journeys to school. World Transport Policy and Practice 1, 29-36

Kahneman, D. and Tversky, A. 1973. On the psychology of prediction. Psychological Review 80, 237251 
Kaur, S. and Nieuwenhuijsen, M.J. 2009. Determinants of personal exposure to PM2.5, ultrafine particle counts, and $\mathrm{CO}$ in a transport microenvironment. Environmental Science \& Technology 43(13), $4737-4743$

Kearns, R.A. and Collins, D.C.A. 2003. Crossing roads, crossing boundaries: autonomy, authority and risk in a child pedestrian safety initiative. Space and Polity 7(2), 193-212

Kingham, S. and Ussher, S. 2007. An assessment of the benefits of the walking school bus in Christchurch, New Zealand. Transportation Research Part A: Policy and Practice 41(6), 502-510

Lally, P., van Jaarsveld, E., et al. 2010. How are habits formed? Modelling habit formation in the real world. Eur J of Soc Psychol 40, 998-1009

Le Tertre, A., Medina, S., et al. 2002. Short-term effects of particulate air pollution on cardiovascular diseases in eight European cities. Journal of Epidemiology \& Community Health 56(10), 773-779

Lee, J.-W. and Jo, W.-K. 2002. Actual commuter exposure to methyl-tertiary butyl ether, benzene and toluene while traveling in Korean urban areas. Science of the Total Environment 291(1-3), 219-228

Lindsay, G., Macmillan, A., et al. 2011. Moving urban trips from cars to bicycles: impact on health and emissions. Australian \& New Zealand Journal of Public Health 35(1), 54-60

Lubans, D.R., Boreham, C.A., et al. 2008. The relationship between active travel to school and healthrelated fitness in children and adolescents: a systematic review. International Journal of Behavioral Nutrition and Physical Activity 8(5), 1-12

Lumsden, L. and Mitchell, J. 1999. Walking, transport and health: do we have the right prescription? Health Promotion International 14, 271-280

Mackett, R.L. and Paskins, J. 2008. Children's Physical Activity: The Contribution of Playing and Walking. Children \& Society 22(5), 345-357 
Marshall, J.D., Brauer, M., et al. 2009. Healthy neighborhoods: walkability and air pollution.

Environmental Health Perspectives 117(11), 1752-1759

Matthews, H., Limb, M., et al. 2000. The 'street as third-space'. In: S. L. Holloway and G. Valentine (Eds). Children's geographies: playing, living, learning. London, Routledge: 63-79.

McDonald, N.C. 2007. Active transportation to school: trends among U.S. school children, 1969-2001. Am J Prev Med 32(6), 509-516

McKee, R., Mutrie, N., et al. 2007. Promoting walking to school: results of a quasi-experimental trial. $J$ Epidemiol Community Health 61, 818-823

McMichael, A.J., Butler, C.D., et al. 2003. New Visions for Addressing Sustainability. Science 302, $1919-1920$

Michie, S., Ashford, S., et al. In press A refined taxonomy of behaviour change techniques to help people change their physical activity and healthy eating behaviours - The CALO-RE taxonomy. Psychology \& Health

Michie, S., van Stralen, M.M., et al. 2011. The Behaviour Change Wheel: a new method for characterising and designing behaviour change interventions. Implementation Science 23(6)

Mitchell, G. and Dorling, D. 2003. An environmental justice analysis of British air quality. Environment and Planning A 35, 909-929

Mudu, P., Martuzzi, M., et al. 2006. Health effects and risks of transport systems: the HEARTS project. W. H. Organization. Copenhagen, World Health Organization Regional Office for Europe Namdeo, A. and Stringer, C. 2008. Investigating the relationship between air pollution, health and social deprivation in Leeds, UK. Environment International 34(5), 585-591

National Statistics 2009. Reported Road Casulaties Great Britain: Main Results 2009. Department of Transport Statistics Bulletin (10)17 
O'Neill, M.S., Jerrett, M., et al. 2003. Health, wealth, and air pollution: advancing theory and methods. Environmental Health Perspectives 111(16), 1861-1870

Office for National Statistics 2000. UK 2000 Time Use Survey

Ogilvie, D., Foster, C.E., et al. 2007. Interventions to promote walking: systematic review. BMJ 334(7605), 1204

Pless-Mulloli, T., Hodgson, S., Namdeo, A. Social Impacts and Social Equity Issues in Transport Workshop Series. Workshop 2: Health Perspectives. Available from http://www.tsu.ox.ac.uk/research/uktrcse/UKTRC-workshop_report2.pdf

Pooley, C.G., Turnbull, J., et al. 2005. The journey to school in Britain since the 1940s: continuity and change. Area 37(1), 43-53

Rissel, C.E. 2009. Active travel: a climate change mitigation strategy with co-benefits for health. New South Wales Public Health Bulletin 20(1-2), 10-13

Rotko, T., Kousa, A., et al. 2001. Exposures to nitrogen dioxide in EXPOLIS-Helsinki: microenvironment, behavioral and sociodemographic factors. Journal of Exposure Analysis and Environmental Epidemiology 11(3), 216-223

Rowland, D., DiGuiseppi, C., et al. 2003. Randomised controlled trial of site specific advice on school travel patterns. Arch Dis Child 88, 8-11

Sabin, L.D., Behrentz, E., et al. 2005. Characterizing the range of children's air pollutant exposure during school bus commutes. Journal of Exposure Analysis and Environmental Epidemiology 15(5), 377-387

Sanger, C. 2005. Girls and the getaway: Cars, culture, and the predicament of gendered space. University Of Pennsylvania Law Review 144(2), 705-756 
Schoemaker, P.J.H. 1982. The Expected Utility Model: Its Variants, Purposes, Evidence and Limitations. Journal of Economic Literature 20, 529-563

Shiffman, S., Stone, A.A., et al. 2008. Ecological Momentary Assessment. Annu. Rev. Clin. Psychol 4

Sjole, A. and Thuen, F. 2002. School journeys and leisure activities in rural and urban adolescents in Norway. Health Promotion International 17, 21-30

Sniehotta, F.F. 2009. Towards a theory of intentional behaviour change: Plans, planning, and selfregulation. British Journal of Health Psychology 14, 261-273

Solnit, R. 2000. Wanderlust: a history of walking. New York, Penguin.

Strack, F. and Deutsch, R. 2004. Reflective and Impulsive Determinants of Social Behavior. Personality and Social Psychology Review 8(3), 220-247

Thambrian, T. and Dian, R.D. 2011. Air pollution and climate change co-benefit opportunities in the road transportation sector in Durban, South Africa. Atmospheric Environment 45, 2683-2689

The Scottish Government 2008. Good places, better health, a new approach to environment and health in Scotland

Timperio, A., Ball, K., et al. 2006. Personal, family, social, and environmental correlates of active commuting to school. Am J Prev Med 30(1), 45-51

Tolley, R. 1990. The greening of urban transport: planning for walking and cycling in Western cities London, Belhaven Press.

Triandis, H. 1977. Interpersonal behavior. Monterey, Brooks-Cole.

Valentine, G. 1996. Children should be seen and not heard: the production and transgression of adults' public space. Urban Geography 17, 205-220 
Valentine, G. 1997. Oh yes I can.' 'Oh no you can't.' Children's and parents' understanding of kids' competence to negotiate public space carefully. Antipode 29, 65-89

van Sluijs, E.M.F., Fearne, V.A., et al. 2009. The contribution of active travel to children's physical activity levels: cross-sectional results from the ALSPAC study. Preventive Medicine 48(6), 519-524

Web, T.L., Sniehotta, F.F., et al. 2010. Using theories of behaviour change to inform interventions for addictive behaviours. Addiction 105, 1879-1892

Wen, L.M., Fry, D., et al. 2008. Factors associated with children being driven to school: implications for walk to school programs. Health Educ Res 23(2), 325-334

Whitelegg, J. 1997. Critical mass: transport, environment and society in the twenty-first century. London, Pluto Press.

Whitelegg, J. 2003. Earthscan reader on world transport policy and practice. London, Earthscan.

Wilson, E.J., Wilson, R., et al. 2007. The implications of school choice on travel behavior and environmental emissions. Transportation Research Part D: Transport and Environment 12(7), 506518

World Health Organization 2009. Protecting health from climate change. Connecting science, policy and people

Yeung, J., Wearing, S., et al. 2008. Child transport practices and perceived barriers in active commuting to school. Transportation Research Part A: Policy and Practice 42(6), 895-900

Zhu, Y., Eiguren-Fernandez, A., et al. 2007. In-cabin commuter exposure to ultrafine particles on Los Angeles freeways. Environ Sci Technol 41(7), 2138-2145

Zuurbier, M., Hoek, G., et al. 2010. Commuters' exposure to particulate matter air pollution is affected by mode of transport, fuel type, and route. Environmental Health Perspectives 118(6), 783-789 
Figure 1:

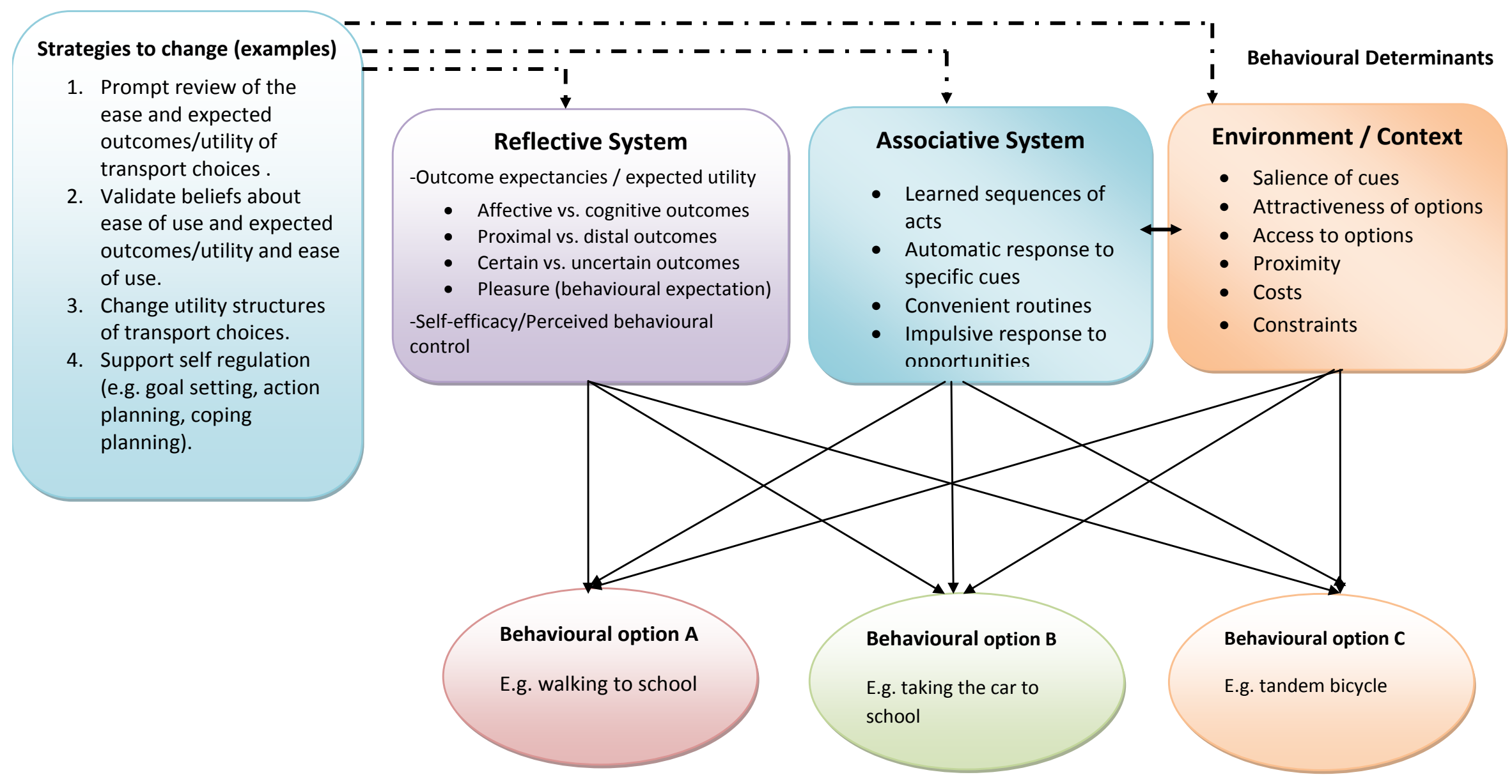

Behavioural Alternatives 
Figure 2

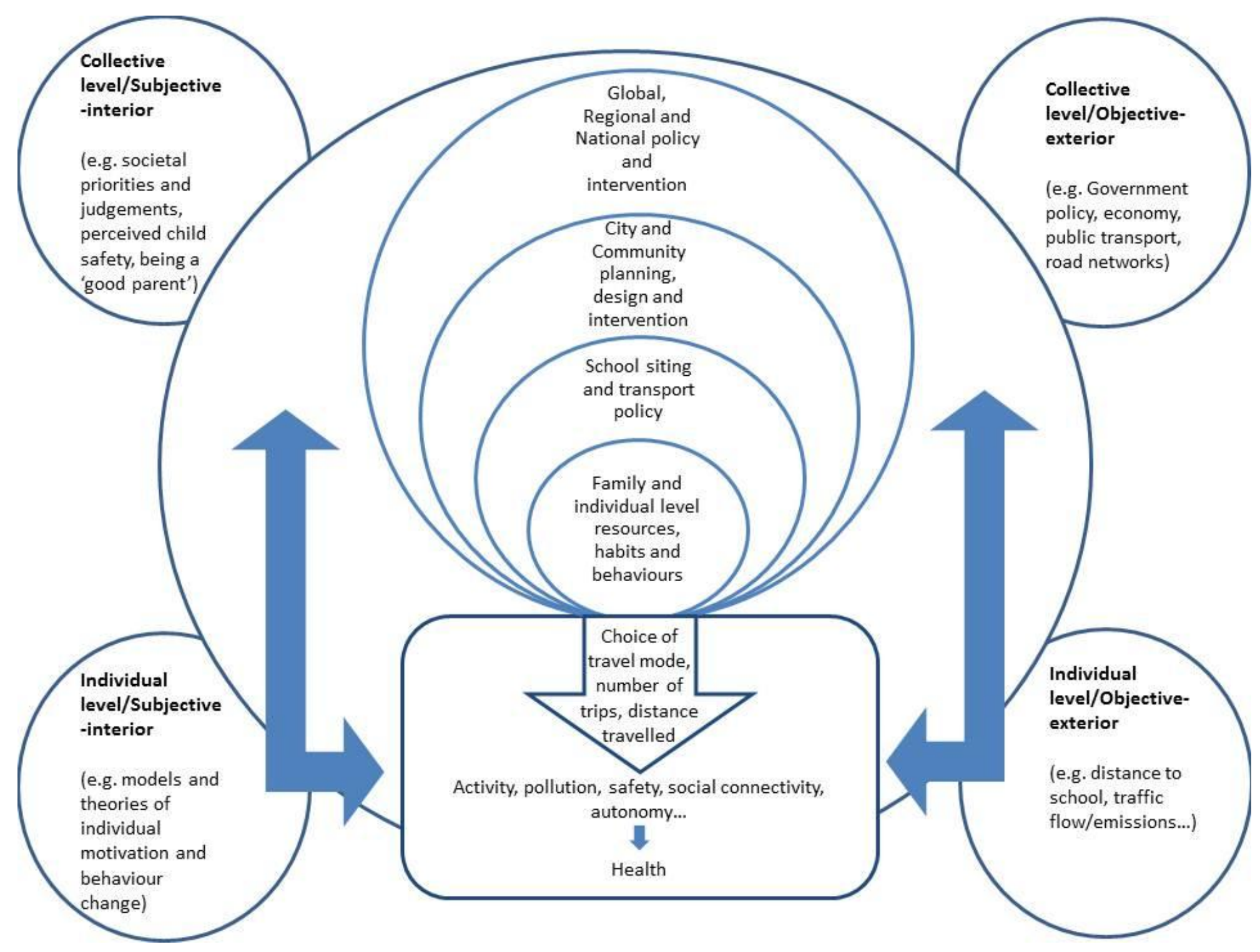

